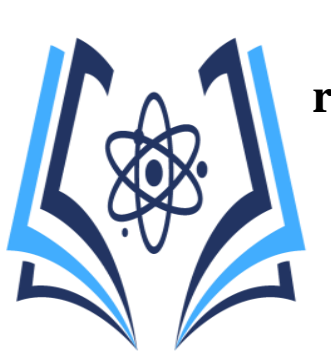

\title{
Síndrome de distrés respiratorio y protocolo de reanimación cardiopulmonar en pacientes neonatos
}

\author{
Respiratory distress syndrome and cardiopulmonary \\ resuscitation protocol in neonatal patients
}

Síndrome de distrés respiratorio y protocolo

Adrián Loor Cedeño ${ }^{1}$

Jaqueline Delgado Molina ${ }^{2}$

${ }^{1}$ Universidad Estatal del Sur de Manabí. viejoloor72@ hotmail.com, https://orcid.org/0000-0003-0667$464 \mathrm{X}$

Recibido: 29-09-2019

Aprobado: 15-12-2019
Contacto: viejoloor72@hotmail.com

\section{Resumen}

La presente investigación está basada en una revisión bibliográfica, el problema principal que motivó esta investigación fué la elevada tasa de incidencia de distrés respiratorio neonatal y su inclusión como una de las principales causas de muertes neonatales según los datos estadísticos del Instituto Nacional de Estadísticas y Censo en el año 2018, así como la importancia de describir la eficacia del protocolo de reanimación cardiopulmonar, herramienta fundamental que se puede ver afectado por diversos factores que pueden incidir en el éxito o fracaso como parte del tratamiento. El objetivo general de la investigación fue describir el síndrome de distrés respiratorio y el protocolo de reanimación cardiopulmonar intrahospitalario en neonatos. Los métodos utilizados fueron el analítico y descriptivo, la técnica que se utilizó fué la revisión bibliográfica con fuentes actualizadas y pertinentes al tema de investigación, Los resultados más relevantes mostraron que un número muy considerable de neonatos a nivel mundial mueren en el primer mes después del nacimiento y también en las primeras 24 horas de vida debido a partos prematuros, complicaciones en el parto y asfixia neonatal, se llegó a la conclusión que el distrés respiratorio neonatal es una complicación que compromete gravemente la vida extrauterina del neonato existiendo la posibilidad de ocasionar algún daño derivado de la aplicación del protocolo de reanimación cardiopulmonar, pero la gravedad de estos dependerá de las situaciones especiales que se presenten durante la aplicación del mismo.

Palabras claves

Asfixia neonatal, complicaciones neonatales, causas de muerte neonatal.

Summary
The present investigation is based on a bibliographic review, the main problem that motivated this investigation was the high incidence rate of neonatal respiratory distress and its inclusion as one of the main causes of neonatal deaths according to statistical data from the National Institute of Statistics and Census in 2018, as well as the importance of describing the efficacy of the cardiopulmonary resuscitation protocol, a fundamental tool that can be affected by various factors that can influence success or failure as part of treatment. The general objective of the research was to describe the respiratory distress syndrome and the protocol of in-hospital cardiopulmonary resuscitation in neonates. The methods used were analytical and descriptive, the technique used was the bibliographic review with updated sources pertinent to the research topic. The most relevant results showed that a very considerable number of newborns worldwide die in the first month after birth. birth and also in the first 24 hours of life due to premature deliveries, complications in labor and neonatal asphyxia, it was concluded that neonatal respiratory distress is a complication that seriously compromises the extrauterine life of the newborn, with the possibility of causing some damage derived from the application of the cardiopulmonary resuscitation protocol, but the severity of these will depend on the special situations that arise during the application of the protocol.

\section{Keywords}

Neonatal asphyxia, neonatal complications, causes of neonatal death. 


\section{Introducción}

Para el neonato, el parto es un desafío natural que marca la transición desde la vida intrauterina a la vida extrauterina. La mayoría de los recién nacidos pueden tener un obstáculo, el $90 \%$ de ellos no necesita ninguna intervención médica para sobrevivir, pero entre $5 \%$ y el $10 \%$ necesita reanimación cardiorrespiratoria. (efren montalvo, 2017) Las intervenciones van a depender del estado de gravedad del neonato, algunos pueden requerir desde una sencilla estimulación táctil hasta una reanimación cardiopulmonar avanzada.

El paro cardiopulmonar (PCR) se define como cese inesperado, brusco y potencialmente reversible de las funciones respiratorias y/o cardiocirculatorias espontáneas, es de vital importancia el reconocimiento de esta situación y el inicio inmediato de las maniobras de reanimación cardiopulmonar, dado que por cada minuto que se pierde, disminuyen las posibilidades de recuperación de la persona. (moran bravo, 2016)

El paro cardiorrespiratorio es la interrupción repentina y simultanea de la respiración y el funcionamiento del corazón, produce una disminución brusca del transporte de oxígeno que da lugar a una disfunción del cerebro las cuales conducen a lesiones celulares irreversibles en el organismo por la anoxia tisular y a la muerte biológica. (moran bravo, 2016)

En neonatos el paro cardiaco es predominante por asfixia, es la causa principal que condiciona la necesidad de reanimación cardiopulmonar del recién nacido $(\mathrm{RN})$ en el momento del parto. (g. paredes, 2010)

En el mundo aproximadamente un $10 \%$ de neonatos necesitara algún tipo de asistencia y solo el $1 \%$ de maniobras de resucitación. 8 de cada 1.000 requerirá ventilaciones a presión positiva y solo 2 de 1.000 intubaciones endotraqueal. (efren montalvo, 2017) En Ecuador, según el Registro Estadístico de Nacidos Vivos y Defunciones 2017, se registraron una tasa de mortalidad neonatal del 5,6 por cada 1.000 nacidos vivos. (censos, 2010)

La Organización Mundial de la Salud (OMS) en el 2017 estimó que, unos 2.5 millones de niños murieron en su primer mes de vida: la mayor parte de las defunciones de recién nacidos $(75 \%)$ ocurren durante la primera semana de vida, y aproximadamente 1 millón de recién nacidos mueren en las 24 primeras horas de vida. Los partos prematuros, las complicaciones relacionadas con el parto, incluida la asfixia perinatal, y las infecciones neonatales causaron la mayor parte de las defunciones de recién nacidos en 2016. (OMS, 2016)

La eficacia del protocolo de reanimación cardiopulmonar va depender, de determinados factores que pueden ayudar en una respuesta positiva o negativa. Se puede tener el mejor protocolo seguir los pasos, pero si no se cuenta con un personal capacitado en reanimación no va servir de nada. (moreno r, 2019)

El síndrome de dificultad respiratoria o síndrome de distrés respiratorio es un trastorno respiratorio de los recién nacidos prematuros en el cual los sacos de aire (alvéolos) de sus pulmones no permanecen abiertos por la falta o la producción insuficiente de la sustancia que los recubre (surfactante). (MANUAL MSD, 2016)

En los recién nacidos afectados, los pulmones están rígidos y los sacos de aire tienden a colapsarse completamente, vaciando los pulmones de aire. En algunos recién nacidos muy prematuros, los pulmones pueden estar tan rígidos que los $\mathrm{RN}$ son incapaces de empezar a respirar en el momento de nacer. Más frecuentemente, los recién nacidos intentan respirar, pero dado que los pulmones están tan rígidos, se produce una dificultad respiratoria grave (distrés respiratorio). (research, 2015)

$\mathrm{Si}$ no se contrarresta con medidas de reanimación, el paro cardiorrespiratorio produce una disminución brusca del transporte de oxígeno que da lugar a una disfunción del cerebro inicialmente $y$, posteriormente, conduce a lesiones celulares irreversibles en el organismo por la anoxia tisular y a la muerte biológica. (Gallo, Mouly, \& Castro, 2017)

La actitud terapéutica a seguir ante la PCR en neonatos debe realizarse de modo protocolizado, según las técnicas de RCP establecidas. Una vez confirmado el PCR debe comenzar a realizarse la reanimación cardiopulmonar básica cuyo fin es conseguir una oxigenación urgente a los Órganos vitales. (Tamez \& Pantoja, 2008)

\section{Etiología}

Existen algunos factores que pueden causar paro cardiorrespiratorio en el recién nacido. Conocerlos permite anticiparse a este cuadro. Entre estos factores se destacan:

1. Problemas respiratorios (neumonías, aspiración, hipertensión pulmonar, síndrome de dificultad respiratoria, neumotórax).

2. Trastorno en el sistema nervioso central (convulsiones, hidrocefalia, hemorragias intracraneales, meningitis).

3. Alteraciones cardiovasculares (shock cardiogenico, insuficiencia cardiaca congestiva, cardiopatías congénitas, arritmias cardiacas graves, shock hipovolémico, deshidratación). 
4. Alteraciones metabólicas (alteraciones hidroelectrolíticas y metabólicas).

5. Causas iatrogénicas (administración intravenosa rápida de soluciones con calcio o con potasio)

6. Shock séptico. (Tamez \& Pantoja, 2008)

Causas

En recién nacidos las causas que con más frecuencia conducen a PCR son:

- asfixia neonatal

- $\quad$ síndrome hipóxico-isquémico cerebral

- hemorragia cerebral.
- insuficiencia respiratoria aguda secundaria a membrana hialina.

- $\quad$ aspiración pulmonar

- malformaciones congénitas graves. (Garcia , Jiménez, \& Porto, 2009)

Cuadro clínico

Conociendo los signos que indican una parada cardiorrespiratoria inminente, ya que un porcentaje de los neonatos que presentan una parada lo hacen tras un periodo de descompensación clínica. ( Palacios \& Ordóñez, 2019)

\begin{tabular}{|c|ll|}
\hline & $\bullet$ & Frecuencia demasiado alta. \\
& $\bullet$ & Trabajo respiratorio exagerado o signos de \\
Fallo respiratorio & & agotamiento. \\
& - & Cianosis. \\
& - & Respiración superficial. \\
& $\bullet$ & Ruidos respiratorios: estridor, sibilancias. \\
\hline \multirow{3}{*}{ Fallo circulatorio } & $\bullet$ & Taquicardia/bradicardia. \\
& $\bullet$ & Mala perfusión periférica. \\
& $\bullet$ & Pulsos débiles. \\
\hline Alteraciones neurológicas & $\bullet$ & Oliguria. \\
\hline
\end{tabular}

\section{Neonatos}

Se considera neonato al producto vivo de la concepción que tiene 37 a 42 semanas de gestación y que está en condiciones óptimas para adaptarse al nuevo ambiente extrauterino.

\section{Clasificación por edad gestacional y peso}

Según la edad gestacional:

1. De pre término: menor de 37 semanas.

- Pre términos tardíos (34 a 36 semanas 6 días)

- $\quad$ Pre término moderados (32 a 33 semanas 6 días)

- Muy pre término (28 a 31 semanas 6 días)
- Pre términos extremos (menor o igual a 27 semanas 6 días)

2. De término: entre 37 y 42 semanas.

3. De pos término: mayor de 42 semanas.

Según su peso al nacer, en relación con los percentiles 10 y 90 :

1. Pequeño para su edad gestacional (PEG),

2. Adecuado para su edad gestacional (AEG).

3. Grande para su edad gestacional (GEG). (Bonito, 2012)

Test de Apgar

Que evalúa. (Gesteiro, Sánchez, Perea, Esparrago, \& Bastida, 2019)

\begin{tabular}{|c|c|c|c|}
\hline Signos clínicos & 0 punto & 1 punto & 2 punto \\
\hline Frecuencia cardiaca. & No se detecta latidos & $<100$ & $>100$ \\
\hline Respiración & No respira & Lenta o irregular & Llora \\
\hline Tono muscular. & Músculos fláccidos & Hipotonía muscular & Movimiento activo \\
\hline Irritabilidad. & No hay reacción. & Gesticulación o muecas & $\begin{array}{l}\text { Gesticulaciones y una } \\
\text { tos, estornudo o llanto } \\
\text { vigoroso. }\end{array}$ \\
\hline Color de la piel & Azul o pálido & $\begin{array}{c}\text { Cuerpo rosado y } \\
\text { extremidades azules. }\end{array}$ & $\begin{array}{c}\text { Todo el cuerpo es } \\
\text { rosado. }\end{array}$ \\
\hline
\end{tabular}




\section{HIGÍA DE LA SALUD}

Casi siempre un puntaje de APGAR bajo es causado por:

- Parto difícil

- Cesárea

- Líquido en la vía respiratoria del bebé
ISSN 2773-7705

Periodo. Julio - Diciembre 2019

Vol. 1, Nro. 1, Publicado 2019-12-31

Un bebé con un puntaje de Apgar bajo, puede necesitar:

- Oxígeno y despejar las vías respiratorias para ayudar con la respiración.

- Estimulación física para lograr que el corazón palpite a una tasa saludable. (Kaneshiro, 2018)

Test de Silverman- Anderson

Que evalúa.

\begin{tabular}{|c|c|c|c|}
\hline Signos clínicos & O punto & 1 punto & 3 punto \\
\hline Aleteo nasal & Ausente & Mínima & Marcada \\
\hline Quejido respiratorio & Ausente & $\begin{array}{c}\text { Audible con el } \\
\text { estetoscopio }\end{array}$ & Audible \\
\hline Tiraje intercostal & Ausente & Apenas visible & Marcada \\
\hline Retracción esternal. & Sin retracción & Apenas visible & Marcadas \\
\hline $\begin{array}{c}\text { Disociación } \\
\text { toracoabdominal }\end{array}$ & Sincronizado & Retraso en inspiración & Bamboleo \\
\hline
\end{tabular}

. (Sanchez, 2013)

\section{REANIMACIÓN CARDIOPULMONAR NEONATAL}

La reanimación cardiopulmonar (RCP) básica es el conjunto de maniobras que permiten identificar si un niño está en parada cardiorrespiratoria (PCR), y realizar una sustitución de las funciones respiratoria $\mathrm{y}$ circulatoria, sin ningún equipamiento específico, hasta que la víctima pueda recibir un tratamiento más cualificado. La RCP básica hay que iniciarla lo antes posible. Su objetivo fundamental es conseguir la oxigenación de emergencia para la protección del SNC y otros órganos vitales. (guzaman fernandez, 2019)

$E I A B C$ de la reanimación neonatal:

Los pasos en la reanimación de un neonato siguen el bien conocido $\mathrm{ABC}$ de la reanimación:

- Establecer una vía respiratoria permeable.

$>$ Colocar al neonato en posición correcta.

$>$ Aspirar la boca, nariz y en ocasiones tráquea.

$>\mathrm{Si}$ es necesario, intubación endotraqueal (IET).

- Iniciar la respiración.

$>$ Aplicar estímulos táctiles para iniciarla.

$>$ Emplear ventilación con presión positiva usando bolsa y mascarilla o bolsa e intubación endotraqueal.

- Mantener la circulación.

$>$ Proporcionar masaje cardiaco.

$>$ Administrar medicamentos
- Se debe colocar al neonato en decúbito supino en posición de olfateo con ligera extensión de la cabeza. Introducir el laringoscopio por la derecha desplazando la lengua hacia la izquierda. Avanzar la hoja del laringoscopio hasta situar la punta en la valécula epiglótica o hasta deprimir calzar la epiglotis. En ocasiones una ligera presión externa sobre la laringe con el quinto dedo de la mano izquierda o efectuada por un ayudante puede facilitar la visualización de las cuerdas vocales. Introducir el tubo endotraqueal con la mano derecha y retirar el laringoscopio con precaución de no desplazar el tubo. Posteriormente fijar el tubo y conectarlo al sistema de ventilación. (guia de reanimacion cardiopulmonar, 2010)

- Para minimizar la hipoxemia durante la intubación es necesario ventilar con bolsa y mascarilla en las siguientes situaciones: antes de iniciar la intubación, en caso de fracaso de la intubación o, si la frecuencia cardíaca desciende por debajo de 100 lat./min durante la maniobra de intubación, la cual debe suspenderse. Cada intento de intubación no debe durar más de $20 \mathrm{~s}$. (guia de reanimacion cardiopulmonar, 2010)

- Es importante asegurarse de que la colocación del tubo es la adecuada, observando los movimientos torácicos, auscultando la entrada de aire en ambas axilas y sobre el estómago y/o mirando la aparición de vaho en el tubo durante

Técnica: 


\section{HIGÍA DE LA SALUD}

la exhalación. La detección del $\mathrm{CO} 2$ exhalado es útil para comprobar la correcta posición del tubo endotraqueal. $\mathrm{Si}$ no se detecta $\mathrm{CO} 2$ se debe comprobar la posición del tubo mediante laringoscopia directa. (guia de reanimacion cardiopulmonar, 2010)

a) Masaje cardíaco: La asfixia produce hipoxia tisular, vasoconstricción periférica, acidosis, disminución de la contractilidad del miocardio, bradicardia y parada cardíaca. La adecuada ventilación y oxigenación previene en la mayor parte de los casos esta situación. (guia de reanimacion cardiopulmonar, 2010)

La mejor técnica consiste en colocar los pulgares en el tercio inferior del esternón, justo por debajo de la línea media intermamilar, y el resto de los dedos abrazando el tórax. El masaje cardíaco también se puede efectuar comprimiendo el tercio inferior del esternón con los dedos medio y anular. Cada compresión debe alcanzar una profundidad de un tercio del tórax. Debe ser suave y durar al menos la mitad del ciclo compresión/relajación. Los dedos no deben separarse del esternón durante la fase de relajación pero deben permitir que la pared costal vuelva a su posición inicial. (Dra Torres, 2009)

El ritmo de compresión/ventilación debe ser 3/1. Tres compresiones seguidas de una ventilación. Para obtener el ritmo de 90 compresiones y 30 resp./min se deben realizar las 3 compresiones en $1,5 \mathrm{~s}$. Dejando 0,5 s para la ventilación. (Dra Torres, 2009)

El pulso debe ser comprobado cada $30 \mathrm{~s}$, mientras dure la reanimación. El masaje debe mantenerse hasta que la frecuencia cardíaca del recién nacido sea mayor de 60 lat./min.

b) Fármacos: $\mathrm{Si}$ a los 60 segundos de ventilación eficaz y los 30 segundos de relación 3:1 el corazón no recupera ritmo superior a 60 latidos por minuto, pese al masaje cardiaco, es necesario administrar fármacos endovenosos por catéter en vena umbilical. (Dra Torres, 2009)

- Adrenalina: La dosis recomendada es de $10-30 \mathrm{mcg} / \mathrm{Kg}$ vía endovenosa. Puede repetirse cada 3 o 5 minutos. Presentación comercial de Adrenalina en ampollas con $1 \mathrm{mg}$ en $1 \mathrm{~mL}$.

- Bicarbonato: Actualmente no se recomienda en la sala de partos. $\mathrm{Si}$, pese a una adecuada ventilación y compresiones torácicas no
ISSN 2773-7705

Periodo. Julio - Diciembre 2019

Vol. 1, Nro. 1, Publicado 2019-12-31 conseguimos un gasto cardíaco espontáneo efectivo, la reversión de la acidosis intracardíaca puede mejorar la función miocárdica y lograr la circulación espontánea. La dosis recomendada seria $1-2$ $\mathrm{mmol} / \mathrm{Kg}$ diluido a $0.5 \mathrm{mmol} / \mathrm{mL}$ endovenoso lento si $\mathrm{pH}$ inferior a 7.20 a pesar de una ventilación adecuada. Se administrará en neonatología si persiste acidosis metabólica. (Dra Torres, 2009)

En prematuros de menos de 32 semanas de gestación el bicarbonato no está indicado por mayor riesgo de hemorragia intracraneal, salvo situaciones excepcionales.

- Naloxona: La naloxona no se recomienda como parte inicial de la reanimación en paritorio del recién nacido con depresión respiratoria. Antes de administrar naloxona se debe recuperar la frecuencia cardíaca y el color con la ventilación. No se debe administrar naloxona a un hijo de madre adicta a opiáceos ya que puede precipitar un cuadro de abstinencia grave. La dosis recomendada es de 0,1 $\mathrm{mg} / \mathrm{kg}$. Posteriormente el niño debe ser vigilado, repitiéndose la dosis de naloxona cada 2-3 min si reaparecen signos de depresión respiratoria. (Dra Torres, 2009)

- Líquidos: Indicados si sospechamos shock hipovolémico por palidez, mala perfusión y pulso débil con frecuencia superior a 100 lpm. Se recomiendan cristaloides isotónicos $10-20 \mathrm{ml} / \mathrm{Kg}$ antes que seroalbumina $5 \%$ si no se dispone de sangre ORh (-) irradiada y deplecionada de leucocitos. Sería de elección el suero fisiológico $10 \mathrm{~mL} \mathrm{Kg}$ en 5$10 \mathrm{~min}$. En estos momentos se considera que la administración de Bicarbonato, Naloxona, mantener la glucemia en el rango de la normalidad se tendrán en cuenta en los cuidados post reanimación, pero no en la sala de partos. (Dra Torres, 2009)

c) Temperatura: En los niños prematuros dado su mayor riesgo de hipotermia se deben extremar las medidas para evitar la pérdida de calor.

\section{Personal de reanimación neonatal}

En cada nacimiento debe haber por lo menos una persona cuya principal responsabilidad sea el RN. Esta persona debe ser capaz de iniciar la reanimación, incluyendo administración de ventilación con presión positiva (VPP) y masaje cardíaco (MC). 


\section{HIGIA DE LA SALUD}

Esta (s) persona (s) rápidamente deben tener las habilidades necesarias para realizar reanimación avanzada incluyendo intubación endotraqueal, MC y administración de medicamentos. En los partos de alto riesgo, en los que el RN pudiera precisar reanimación, siempre debe estar presente una persona capacitada para realizar todas las maniobras de reanimación. En los partos múltiples debe haber un equipo de reanimación por cada RN. (Dra Torres, 2009)

El trabajo en equipo y las habilidades de comunicación son tan importantes como las habilidades técnicas y cognitivas. Los que reciben (y reaniman) $\mathrm{RN}$ deben:

- Conocer el ambiente de trabajo.
ISSN 2773-7705

Periodo. Julio - Diciembre 2019

Vol. 1, Nro. 1, Publicado 2019-12-31

- Usar toda la información disponible.

- Anticipar y planificar.

- Definir quién tendrá el rol de liderazgo.

- Comunicarse efectivamente.

- Delegar trabajo de manera óptima.

- Dirigir la atención sabiamente.

- Saber usar todos los recursos disponibles.

- Solicitar ayuda cuando corresponde.

- Mantener una conducta profesional.

Equipamiento y ambiente

Antes de cada nacimiento se debe verificar el estado y buen funcionamiento de los equipos y la disponibilidad de suministros. (guia de reanimacion cardiopulmonar, 2010)

\begin{tabular}{|c|c|}
\hline Temperatura. & $\begin{array}{l}\text { Calentador radiante o fuente de calor. } \\
\text { Compresas o toallas tibias. } \\
\text { Gorros. } \\
\text { Bolsa de plástico (para recepción de PT }<32 \text { semanas). } \\
\text { Colchón térmico. }\end{array}$ \\
\hline Vía aérea. & $\begin{array}{l}\text { Pera de goma para aspiración. } \\
\text { Sonda de aspiración con circuito de aspiración. } \\
\text { Aspirador de pared con manómetro de presión. } \\
\text { Estetoscopio. }\end{array}$ \\
\hline Ventilación. & $\begin{array}{l}\text { Mezclador de oxígeno y aire para entregar } \mathrm{FiO}_{2} \text {, según objetivos de } \\
\text { saturación preductal. }\end{array}$ \\
\hline Oxigenación-FC. & $\begin{array}{l}\text { Oxímetro de pulso - monitor ECG. } \\
\text { Tablas con las recomendaciones de objetivo de saturación preductal. } \\
\text { Equipos para entregar oxigeno libre. }\end{array}$ \\
\hline Intubación. & $\begin{array}{l}\text { Laringoscopio con ramas de hoja recta tamaños } 00-0 \text { y } 1 . \\
\text { Tubos endotraqueales. Tamaños } 2.5,3 \text { y } 3.5(\mathrm{~mm}) \text {. } \\
\text { Cinta métrica y/o tabla con la profundidad de inserción del TET. } \\
\text { Tijeras. } \\
\text { Cinta o tela adhesiva para fijación del TET. } \\
\text { Máscaras laríngeas. } \\
\text { Cánulas de mayo para RN. }\end{array}$ \\
\hline Medicación. & $\begin{array}{l}\text { Adrenalina. } \\
\text { Solución fisiológica. } \\
\text { Catéteres umbilicales para la administración de medicamentos. } \\
\text { Jeringas de } 1,3,5 \text { y } 10 \mathrm{ml} \text {. }\end{array}$ \\
\hline
\end{tabular}

Factores de riesgo

\begin{tabular}{|l|l|}
\hline \multicolumn{1}{|c|}{ Previo al parto. } & \multicolumn{1}{c|}{ Intraparto. } \\
\hline -Embarazo sin control prenatal. & -Narcóticos administrados a la madre \\
-Gestación pre término o post término. & 4 horas previa al parto. \\
-Embarazo múltiple. & -Desprendimiento de placenta, placenta \\
-Patologías maternas: renal, pulmonar, neurológica, & previa. \\
tiroidea. & -Prolapso de cordón. \\
-Diabetes gestacional o previa. & -Alteración en la frecuencia cardíaca fetal. \\
-Hipertensión inducida por embarazo o crónica. & -Hemorragia durante el parto. \\
-Adicción, tabaquismo, alcoholismo materno. & -Líquido amniótico meconial, sanguinolento o \\
-Infección materna, malformaciones fetales, hidrops & purulento. \\
fetalis. & -Corioamnionitis. \\
-Oligohidramnios o polihidramnios. & -Parto prolongado. \\
-Restricción de crecimiento intrauterino. & -Macrosomía, distocia de hombros. \\
-Macrosomía fetal. & -Presentación anormal. \\
-Hemorragia durante el segundo o tercer & -Utilización de fórceps. \\
Semestre. & -Cesárea de urgencia. \\
-Ruptura prematura de membranas. & -Anestesia general. \\
\hline
\end{tabular}




\section{HIGÍA DE LA SALUD}

Cuidados de enfermería en la reanimación neonatal

- Recepción del RN en sábanas tibias, colocarlo bajo una fuente de calor radiante y secarlo inmediatamente, para evitar la hipotermia que es un factor que agudiza el cuadro depresivo.

- Poner al RN en posición decúbito supino con el cuello ligeramente extendido, para abrir la epiglotis.

- Permeabilizar vías aéreas, si las secreciones son muy abundantes, sanguinolentas $\mathrm{o}$ hay presencia de meconio, se realiza aspiración bucofaríngea con presión negativa.

- Las aspiraciones deben ser delicadas para evitar traumatismo en la mucosa oral.

- Posteriormente se retiran las secreciones de la nariz mediante peras.

- Aspirar antes del primer llanto, para evitar la broncoaspiración y que el contenido se aloje en las vías respiratorias bajas.

- Evaluar el estado del RN, tomar decisiones oportunas y aplicar las acciones inmediatamente, el tiempo es un factor primordial en la evolución del paciente. (guia de reanimacion cardiopulmonar, 2010)

Personal de reanimación neonatal

En cada nacimiento debe haber por lo menos una persona cuya principal responsabilidad sea el RN. Esta persona debe ser capaz de iniciar la reanimación, incluyendo administración de ventilación con presión positiva (VPP) y masaje cardíaco (MC).

Esta (s) persona (s) rápidamente deben tener las habilidades necesarias para realizar reanimación avanzada incluyendo intubación endotraqueal, MC y administración de medicamentos. En los partos de alto riesgo, en los que el RN pudiera precisar reanimación, siempre debe estar presente una persona capacitada para realizar todas las maniobras de reanimación. En los partos múltiples debe haber un equipo de reanimación por cada RN. (Dra Torres, 2009)

El ciclo que es fundamental para el éxito de la reanimación, sigue una pauta que implica un proceso continuo de evaluación-decisión-acción. Las decisiones y acciones de la reanimación se basan en la evaluación sucesiva de 3 signos clínicos en el RN:
Periodo. Julio - Diciembre 2019 Vol. 1, Nro. 1, Publicado 2019-12-31

1. Esfuerzo respiratorio: puede estar presente o ausente, ser eficaz o no.

2. Frecuencia cardíaca: se determina si es inferior o superior a 100 latidos/min.

3. Coloración: cianosis central o palidez.

Esfuerzo respiratorio: Si el RN está en apnea o con respiración irregular tipo jadeo, se efectúa una estimulación táctil, en caso de no responder en los primeros 30 segundos de vida, se inicia ventilación con presión positiva (VPP) utilizando bolsa autoinflable o de anestesia a través de una mascarilla acorde con el peso del RN con oxígeno adicional. La persona que realiza la reanimación debe evaluar la gravedad de la depresión respiratoria de acuerdo con los antecedentes y aspecto del niño. La ausencia de esfuerzo respiratorio, la presencia de cianosis central y flacidez completa, son signos de gravedad. (Lic. Frank W. Castro López, 2007)

Frecuencia cardíaca: Si es inferior a 100 latidos por minuto, aunque parezca aceptable o no el esfuerzo respiratorio, se debe iniciar la VPP con máscara; la frecuencia cardíaca por debajo de 100 latidos/min especialmente si no responde a la VPP, necesita de las acciones de urgencia y se procede al masaje cardíaco, alternando 3 compresiones por cada insuflación pulmonar, para mantener oxigenados los órganos vitales. (Lic. Frank W. Castro López, 2007)

Coloración: La cianosis distal de las extremidades es una condición que afecta a la mayoría de los niños en los primeros minutos de vida, por tanto, no requiere de ninguna acción. Si el RN presenta cianosis central, se debe administrar oxígeno en la mayor concentración posible. En los RN que tienen buen esfuerzo respiratorio y una frecuencia cardíaca por encima de 100 latidos/min y que presenten una cianosis persistente que no responde a la administración de oxígeno libre, hay que estar alerta a que se alteren la respiración y la frecuencia cardíaca y que eventualmente requieran VPP. Por lo que se debe estudiar la causa de la cianosis mantenida, así como descartar la posibilidad de una cardiopatía congénita cianótica. (Lic. Frank W. Castro López, 2007)

\section{Materiales y métodos}

La investigación es de tipo descriptiva, se aplicaron el método analítico y descriptivo, con la técnica de revisión bibliográfica, considerando la actualización y pertinencia de las fuentes consultadas que incluyeron los aspectos más importantes y relevantes inherentes al tema investigado. 


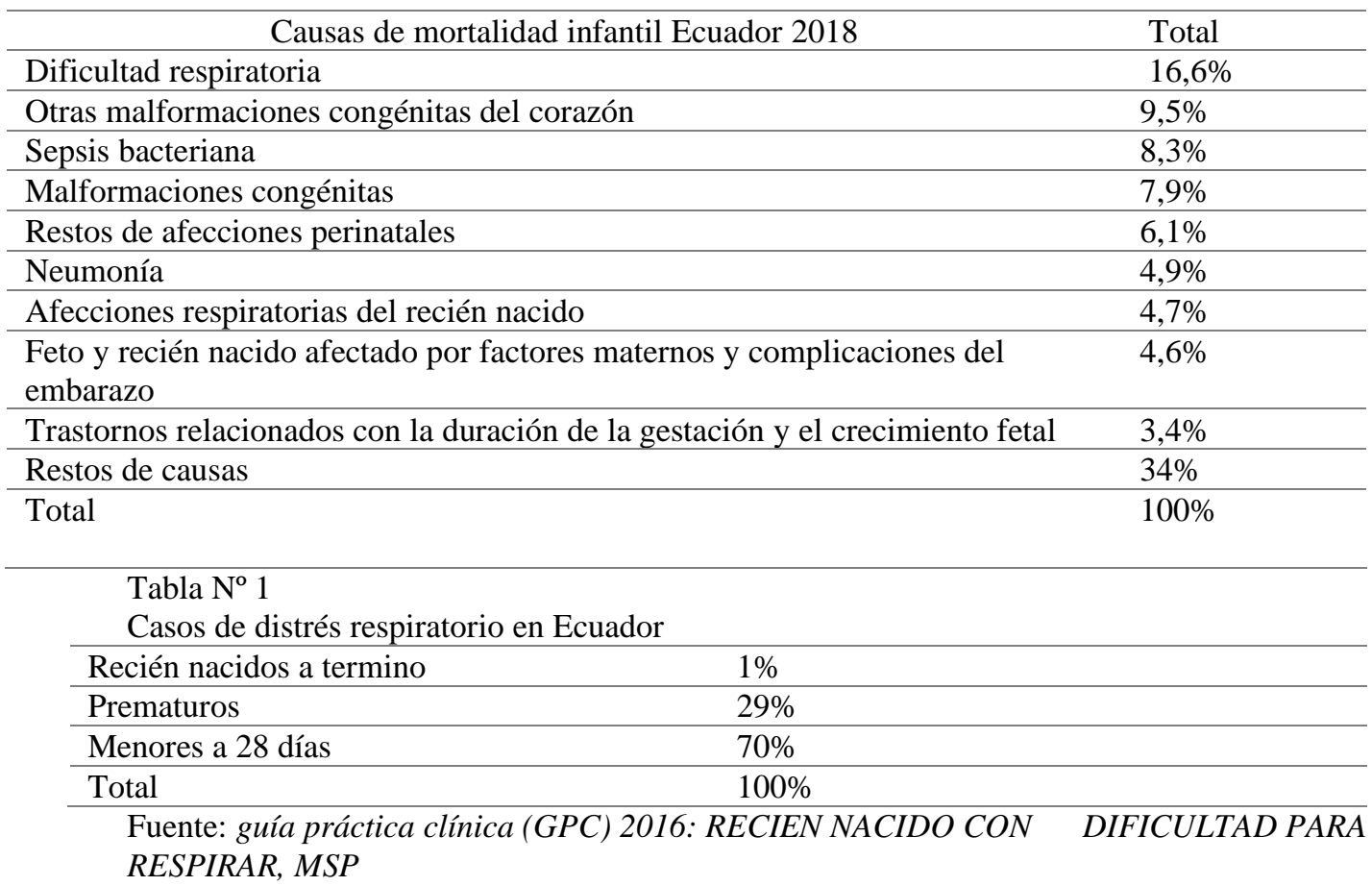

Como podemos apreciar en la tabla $\mathrm{n}^{\mathrm{o}} 1$, el $70 \%$ y $29 \%$ de los casos de distrés respiratorio se presentan en los menores de 28 días y prematuros respectivamente, datos estadísticos que guardan relación con lo descrito en la literatura médica y con lo que se presenta en la realidad que se vive en las instituciones de salud en todos los niveles de atención.

\section{Tabla $\mathrm{N}^{\mathrm{o}} 2$}

Fuente: Instituto Ecuatoriano de censos 2018: mortalidad infantil.

En esta tabla podemos observar que la primera causa de muerte neonatal en el Ecuador en el año 2018, fue la dificultad respiratoria con un $16,6 \%$ de casos, con este dato estadístico se demuestra que los neonatos durante su primer mes de vida pueden sufrir esta complicación debido a ciertos factores como la prematurez y el bajo peso al nacer condicionando su capacidad vital.

\section{Conclusiones}

- Entre los factores de riesgo predisponentes de distrés pulmonar en neonatos que fueron identificados, están las enfermedades que se presentan en el embarazo como la neumonía, hipertensión arterial, y cardiopatías, además de bajo peso en las embarazadas, alcoholismo, tabaquismo, drogadicción y falta de controles prenatales periódicos, también otros factores asociados al producto como la prematurez y el bajo peso al nacer.

- El cuadro clínico principal que se presenta en los neonatos con distrés respiratorio compromete el funcionamiento normal del mecanismo ventilatorio pulmonar, incluyendo signos clínicos de respiración rápida y poco profunda, retracción costal, disnea, taquipnea y cianosis.

- El distrés respiratorio neonatal es una complicación que compromete gravemente la vida extrauterina del neonato existiendo la posibilidad de ocasionar algún daño derivado de la aplicación del protocolo de reanimación cardiopulmonar, pero la gravedad de estos dependerá de las situaciones especiales que se presenten durante la aplicación del mismo. 


\section{Colaboradores de la Investigación:}

Katiusca Castro Córdova; Mireya Chorlango Torres; Kenyi Franco Reyes; Giana Holguín Bello; Joselyn Parrales Sarco; Alison Ponce Ponce; Lilibeth Rodríguez Loor; Jefferson Romero Gonzáles; Leydi Zambrano Obando; Evelyn Zavala Panchana.

\section{Referencias bibliográficas}

Palacios , A., \& Ordóñez, O. (12 de Julio de 2019). Fisterra. Recuperado el 18 de junio de 2020, de Fisterra: https://www.fisterra.com/guias-clinicas/reanimacion-cardiopulmonar-basicapediatria/

Bonito, R. R. (2012). manual de neonatología. Mc Graw Hill.

censos, m. d. (2010). estadisticas y censos .

Dra Torres, J. (2009). Reanimacion neonatal .

efren montalvo, m. m. (2017). insuficiencia respiratoria y sindrome de distress respiratorio . resvista de la facultad de ciencias medicas, 18(1-4).

g. paredes, c. c. (junio de 2010). sindorme de distres respiratorio agudo. scielo, 34(5).

Gallo, S., Mouly, J., \& Castro, E. (Obtubre de 2017). Repositorio institucional digital de acceso abierto unicen. Recuperado el 18 de junio de 2020, de Repositorio institucional digital de acceso abierto UNICEN:

https://www.ridaa.unicen.edu.ar/xmlui/bitstream/handle/123456789/1527/Gallo\%2C\%20Sant iago.pdf?sequence $=1 \&$ isAllowed $=y$

Garcia , T., Jiménez, R., \& Porto, R. (13 de Febrero de 2009). Asociación Española de Pediatría de Atención Primaria. Recuperado el 18 de junio de 2020, de Asociación Española de Pediatría de Atención Primaria: https://www.aepap.org/sites/default/files/RCP.pdf

Gesteiro, E., Sánchez, F., Perea, S., Esparrago, M., \& Bastida, S. (marzo de 2019). Investigadores en Pediatría y Neonatología rendimos homenaje a la Dra Virginia Apgar. Journal of Negative and no positive results, 4(3), 5-6.

(2010). guia de reanimacion cardiopulmonar. colombia.

guzaman fernandez, m. d. (2019). reanimacion cardiopulmonar en neonatologia .

Kaneshiro, N. (10 de Noviembre de 2018). MedlinePlus Información de salud para usted. Recuperado el 18 de junio de 2020, de Medlineplus: https://medlineplus.gov/spanish/ency/article/003402.htm

Lic. Frank W. Castro López, L. O. (2007). Manual de Enfermería en Neonatología ATENCIÓN DE ENFERMERÍA ( Lic. Maura E. Díaz Antúnez ed.). La Habana: Ciencias medicas ECIMED.

MANUAL MSD. (14 de enero de 2016). MANUAL MSD. Recuperado el 22 de junio de 2020, de MANUAL MSD: https://www.msdmanuals.com/es/professional/pediatr\%C3\%ADa/problemasrespiratorios-en-reci\%C3\%A9n-nacidos/s\%C3\%ADndrome-de-dificultad-respiratoria-enreci\%C3\%A9n-nacidos

moran bravo, e. f. (2016). manejo actualizado del paro cardiorespiratorio . UTMACH, ciencias quimicas, machala.

moreno r, v. j. (2019). estudio colaboratibo multicentrico sobre reanimacion cardiopulmonar en nueve unidades de cuidados intensivos pediatricos de la republica de argentina. argentina pediatrica, 3.

OMS. (2016). defunciones de recien nacido .

research, m. e. (2015). sindrome de dificultad respiratoria aguda . mayo clinic. 

Enfermera pediatrica: https://enfermerapediatrica.com/test-de-silverman/

Tamez, R., \& Pantoja, M. (2008). Enfermeria en la unidad de cuidados intesivos neonatal. Buenos Aires: medica Panamericana. 